\title{
Non-uniform fluidization in auto-oscillating mode
}

\section{Yaroslav Kornienko, Serhii Haidai}

\section{National Technical University of Ukraine "Igor Sikorsky Kyiv Polytechnic Institute"}

Keywords:

Hydrodynamics

Pulsation

Fluidization

Fertilizer

Ash

\section{Article history:}

Received 23.05.2017

Received in revised

form 18.08.2017

Accepted 05.09.2017

\section{Corresponding} author:

Serhii Haidai

E-mail:

GaidaiSS@i.ua

DOI: $10.24263 / 2304-$ 974X-2017-6-3-16

\section{Abstract}

Introduction. The objective of this work is mathematical modeling of non-uniform fluidization in an auto-oscillating hydrodynamic mode, which will improve the efficiency of heat and mass transfer along processes of dehydration and granulation by creating an intensive directed mixing of granular material.

Materials and methods. The granular material contained in the granulator chamber, equipped with a special gas distributing device in the lower part and a guiding insert in the upper. Determinations of porosity and pressure drop in a fluidized bed with video recording of the process were carried out using specialized equipment.

Results and discussion. Is implemented the non-uniform fluidization in an auto-oscillating mode with the application of an original gas distributing device with a coefficient of a cross-section coefficient $\varphi=4.9 \%$, and an improved granulator chamber. Is provided an intensive macro mixing of granular material with an equivalent diameter of $D_{e}=3.97 \mathrm{~mm}$ and a density $\rho_{s}=1450 \mathrm{~kg} / \mathrm{m}^{3}$ with relation of the nominal pressure drop to height of a fluidized bed $\Delta P_{\text {bed }} / H_{0} \geq 8500 \mathrm{~Pa} / \mathrm{m}$ with a pulsating frequency $f=1.67 \mathrm{~Hz}$. Non-uniform fluidization in an auto-oscillating mode provides a granulation coefficient $\psi \geq 90 \%$, and the average specific load of the bed surface of granular material by moisture $a_{f}=0.8-0.9 \mathrm{~kg}_{\text {moist }} /\left(\mathrm{m}^{2} \cdot \mathrm{h}\right)$. Mathematical model was chosen and on the basis of experimental researches was modified. The developed mathematical model with taking into account heterogeneity made possible to determine the conditions of realization a process in which up to $25 \%$ of the mass of a fluidized bed is in the active phase outside the bed with a frequency $f=1.67 \mathrm{~Hz}$. The mathematical model with an accuracy of $94.1 \%$ confirms the results of experimental study.

Conclusions. The hydrodynamics in granulator chamber without formation of stagnant zones was realized. The modified mathematical model made possible to determine the intensity of an active pulsating and a volume circulating mixing, that will significantly increase the stability of kinetics of granule formation in dehydration of composite liquid systems. 


\section{Introduction}

By previous studies [1-6] vas found that stability of a difficult dehidratation and granulation process in a fluidized bed with in the presence of phase transitions is determined by the method of interaction of the coolant (gas fluidizing agent) with solid particles $[5,7]$. This is especially true for obtaining granular organic-mineral fertilizers with given properties [1-6].

The purpose of the article is modeling of an auto-oscillating mode of fluidization in chamber of a fluidized-bed apparatus.

\section{Analysis of a literature}

In order to intensify the transfer processes in apparatuses with a fluidized bed in works [8-11] proposed applying the pulsating feed of coolant during working with heat-resistant materials. In particular, [8] the pulsating mode of coolant feeding to a fluidized bed is performed by using a mechanical pulsator. Realization of this method depends on reliability of mechanical pulsator in medium of high-temperature coolant, and this system does not work in auto-oscillating mode.

The method of creating non-uniform fluidization is proposed by authors $[6,7]$ by applying of an original gas distributing device (GDD) [2]. Such construction of GDP with the constructive changes of chamber of an apparatus [2] provides realization of a jetpulsating non-uniform mode of fluidization, which under certain conditions transfers into auto-oscillatory mode.

Experimentally [6-7] found that non-uniform auto-oscillating mode of fluidization when obtaining humic-mineral fertilizers allows increasing in 1.63 times values of the average specific load of the bed surface of granular material by moisture $\left(a_{f}\right)$ in comparison with the traditional bubbling mode of fluidization.

The total surface of granular material determines the minimum height of fixed bed $H_{0}$ in apparatus in carrying out processes of dehydration and granulation of liquid heterogeneous systems in fluidized bed. The ratio of gas torch height $y_{f}$ to $H_{0}-y_{f} / H_{0}<0.5$ causes an implementation of the usual bubble mode of fluidization [12].

Small gas bubbles chaotically pass through a fluidized bed of granular material, bypassing the stagnant zones formed on working surfaces of the gas distributing device (GDD). This leads to melting of material when using a high-temperature coolant. At that, in the heat-mass transfer is involved not the whole surface of granular material particles and therefore this leads to appearing of areas with an over moistened material.

To eliminate these phenomenons and to increase the efficiency of heat and mass transfer processes an intensive local injection of fluidizing agent into a bed of granular material is proposed.

\section{Materials and methods}

\section{Experimental installation}

Investigation of the hydrodynamic mode of fluidization were carried out using the experimental installation of granulator with the chamber sizes $A \times B \times H=0.3 \times 0.11 \times 0.8 \mathrm{~m}$ [13]. To create a jet-pulsing fluidization in an auto-oscillating mode, the chamber of 
granulator in a bottom part is equipped with the gas distribution device (GDD) of a slit-type [2] 8 (Figure 1) and with the guiding insert at the top [2] 9 (Figure 1). The cross-section coefficient of GDD $-\varphi=4.9 \%$, distance (step) between slits $-t=0.114 \mathrm{~m}$.

For video and photo analysis, the front wall of the chamber is transparent.

\section{Materials}

Granular polydisperse product obtained by dehydration of composite liquid systems that contain ammonium sulfate, sunflower ash and humic components was used as a granular material in the apparatus with a fluidized bed [2]. Equivalent diameter of particles was $D_{e}=3.97 \mathrm{~mm}$, density $-\rho_{s}=1450 \mathrm{~kg} / \mathrm{m}^{3}$. Mass of loaded in the apparatus granular material was $M_{b}=7.8 \mathrm{~kg}$, that determined the height of bed with porosity $\varepsilon_{0}=0.4$ $H_{0}=0.32 \mathrm{~m}$ and the nominal hydrostatic pressure $\Delta P_{\text {nom. }}=2780 \mathrm{~Pa}$, Injection height of a primary jet $-\Delta=40 \mathrm{~mm}$.

\section{Measuring complex}

Pressure drop in a fluidized bed was continuously measured by the computerized system with applying of MPXV7007DP - low pressure sensors with an accuracy of $\pm 0.1 \mathrm{~Pa}$ with frequency of 63 measurements per second $(63 \mathrm{~Hz})$ using computer and the Arduino Pro Mini controller. Scheme of devices and sensors placement is shown on Figure1.

Changes of a fluidized bed porosity in time was determined with the use of photo analysis with the step $\Delta \tau=0.04 \mathrm{~s}$.
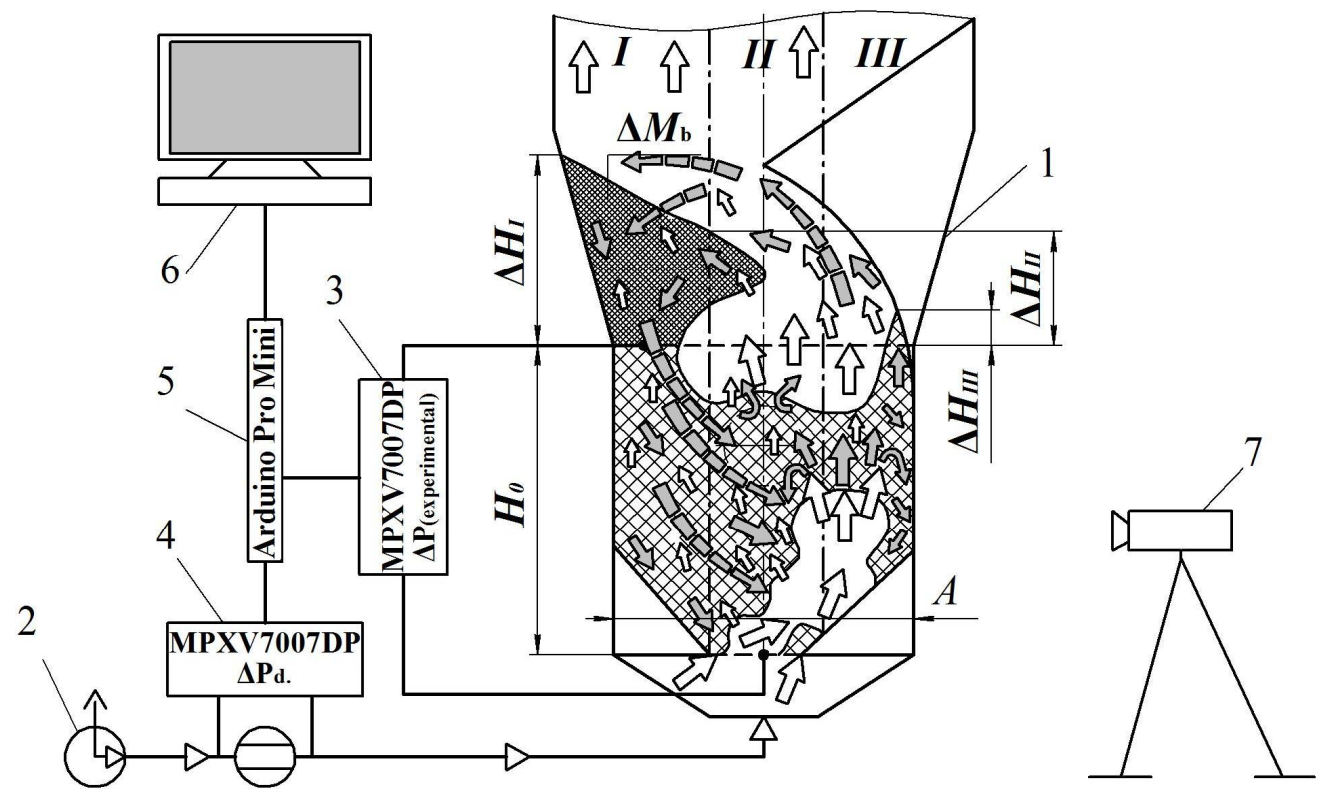

Figure 1. Scheme of computerized system for measuring the pressure drop in the experimental installation

1 - fluidized bed granulator; 2 - gas blower; 3,4 - low pressure sensors; 5 - controller; 6 - computer; 7 - video camera. 


\section{Results and discussion}

\section{Physical modeling of the non-uniform jet-pulsating fluidization in an auto- oscillating mode}

Essence of the method is that the granulator chamber with a given height bed $H_{0}$ is divided into three equal parts (Figure $2 \mathrm{a}$ ). At the conditional limit of the $I I$ and $I I I$ zones, at an altitude $\Delta$ relative to the horizontal axis $x$ in vertical direction through the slit of GDD is injected a gas carrier $-m_{1}$. This leads to the formation of a vertical flat torch with a height $y_{f}$.

A secondary gas jet is injected through the GDD slit in a horizontal direction at a distance $t$ from the first slit, that is equal to length of horizontal jet breakthrough (Figure $2 \mathrm{~b}$ ). At that, mass flow from the second jet $m_{2}>m_{1}$, (Figure $2 \mathrm{~b}$ ).

As a result of combining of two gas mass flows from two jets, a gas bubble with cylindrical (barrel-similar) form with a horizontal axis of symmetry parallel to axis $z$ begins to form on the top of primary vertical torch from the first jet $y_{f}$. Thus, as the inject velocity of a fluidizing agent to this zone significantly exceeds the gas filtration velocity in a fluidized bed of granular material, then size of the gas cylinder (bubble) begin to increase in diameter, and it's width is limited by width of the apparatus chamber $-B$ (Figure 2).

The formed gas cylinder (bubble) tightly adjoins to the vertical walls along axis $z$ and has a minimal clearance with the right vertical wall of the apparatus, (Figure $2 \mathrm{c}$ ).

That is, an elastic gas cavity forms in $I I$ and $I I I$ zones and it begin to move the granular material in the frontal part of the gas bubble.

When the gas bubble reaches a critical size it begin to move with acceleration to the surface of the fluidized bed (Figure $2 \mathrm{~d}$ ), and after exit causes the inertial ejection of the granular material into the over-bed space. The granular material that is ejected from the fluidized bed moves to zone $I$ at the expense of contact with the special guiding device in the the apparatus. In this way the height of a fluidized bed increases (Figure 2). The movement of material from zones $I I$ and $I I I$ occurs until the instant height of granular material in zone $I I I$ will not be equal to $H_{\text {residual }}=y_{f}+\Delta$.

Then the whole inertially ejected material from a fluidized bed moves to the left part of the apparatus with width $A_{\Gamma}=A / 3$ and causes the achievement of the maximum value of $\Delta h_{I}$ (Figure $2 \mathrm{e}$ ). After this begins an intensive sliding down of material from the point $j$ into zones $I I$ and $I I I$ (Figure 2 e) until achievement of the initial equilibrium state (Figure $2 \mathrm{f}$ ). At the moment of an intensive movement of granular material the energy of gas jet is spending on slowing the velocity of particles movement that significantly intensifies the processes of mass transfer. Returning of granular material to the state of equilibrium (initial state) completes a cycle that is subsequently repeated and leads to the auto-oscillating mode of fluidization.

So, unlike the uniform fluidization, the energy supplied with a fluidizing agent is spent on the local injection of energy with the gas phase into a given zone of a fluidized bed, which leads to increasing of the potential energy of bed in 1.5-2 times, and dispersed system is deduced from the state of equilibrium.

Thus, applying of the jet-pulsating mode of fluidization allows to intensify renewing of the surface of phases contact and to increase coefficients of mass transfer between phases. 

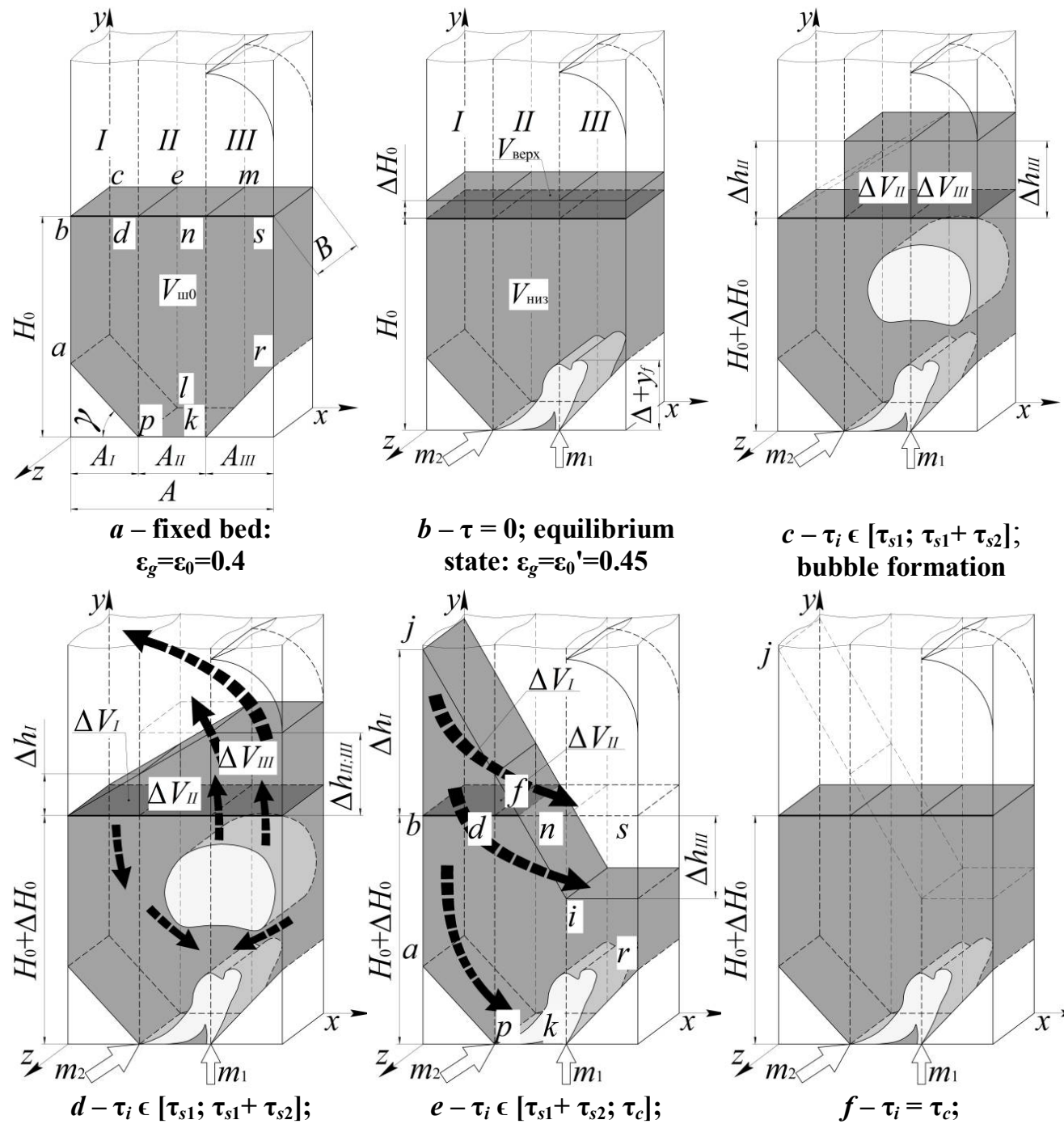

bubble formation

$$
b-\tau=0 \text {; equilibrium }
$$
state: $\varepsilon_{g}=\varepsilon_{0}{ }^{\prime}=0.45$

$$
c-\tau_{i} \in\left[\tau_{s 1} ; \tau_{s 1}+\tau_{s 2}\right]
$$
bubble formation

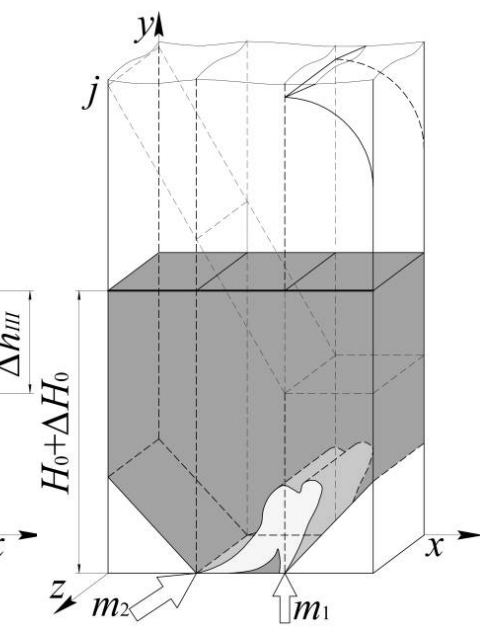

$$
e-\tau_{i} \epsilon\left[\tau_{s 1}+\tau_{s 2} ; \tau_{c}\right]
$$

particles sliding down:

$$
\varepsilon_{g}=\varepsilon_{g(\max )}
$$

$f-\tau_{i}=\tau_{c}$

equilibrium state:

$$
\varepsilon_{g}=\varepsilon_{0}=0.45
$$

Figure 2. A gas and solid phases interaction model in a granulator chamber with a local injection of a fluidizing agent

According to the given physical model, one cycle consists of such stages:

1. Formation of a gas bubble with the partial expansion of bed in zones $I I$ and III $-\tau_{s 1}$

2. Moving of granular material from zones $I I$ and $I I I$ up to the over-bed space (inertial ejection) and then - into zone $I$ with the subsequent increase of the fluidized bed height in this zone $-\tau_{s 2}$;

3. Moving of the granular material in the opposite direction (sliding down) from zone $I$ to 
zones $I I$ and $I I I$, returning the fluidized bed to the initial state (equilibrium state) $-\tau_{s 3}$. Then the total cycle time is:

$$
\tau_{c}=\tau_{s 1}+\tau_{s 2}+\tau_{s 3}
$$

\section{Justification of the mathematical model}

It is quite obvious that the dependence of a fluidized bed height on porosity has a nonlinear character.

To describe this process is advisable to use the approach proposed in work [8].

$$
\frac{d^{2} H\left(\tau_{i}\right)}{d \tau_{i}^{2}}=\frac{\Delta P\left(\tau_{i}\right)}{\rho_{m}\left(1-\varepsilon_{(\text {average })}\left(\tau_{i}\right)\right) H\left(\tau_{i}\right)}-\mathrm{g}
$$

where $\Delta P\left(\tau_{i}\right)$ - current value of hydraulic resistance of granular material present in volume of initial bed (p. $j$ ) with height $H_{0}+\Delta H_{0}$;

$\Delta H_{0}$ - increase in height of a fluidized bed due to formation of gas torch (Figure 2 b).

Calculation of the total hydraulic resistance in fluidized bed was made out according to the equation with structure proposed by the author [14]:

$$
\left(\frac{d P}{d y}\right)_{\text {total }}=\left(\frac{d P}{d y}\right)_{\text {momentum }}+\left(\frac{d P}{d y}\right)_{\text {friction }}+\left(\frac{d P}{d y}\right)_{\text {hydrostatic }}
$$

or in an integral form:

$$
\Delta P_{\text {total }}\left(\tau_{i}\right)=\Delta P_{\text {momentum }}\left(\tau_{i}\right)+\Delta P_{\text {friction }}\left(\tau_{i}\right)+\Delta P_{\text {hydrostatic }}\left(\tau_{i}\right)
$$

To solve this equation it is necessary to determine experimentally the dynamics of change of a fluidized bed porosity values (average and in local zones).

According to the physical model porosity in zone $I$ is constant and accepted as $\varepsilon_{0}=0.4$.

Moving of granular material comes from zones $I I$ and $I I I$ and is associated with formation of gas bubble. Therefore, the equation for determining loss of pressure on displacement of mass from zones $I I$ and $I I I$ is expressed by the values of porosity in these zones $-\varepsilon_{(I I I I I)}$ :

$$
\Delta P_{\text {momentum }}\left(\tau_{i}\right)=\frac{1}{2}\left[\rho_{s} \cdot \varepsilon_{s(I I ; I I)}\left(\tau_{i}\right) \cdot w_{s}\left(\tau_{i}\right)^{2}+\rho_{g} \cdot \varepsilon_{g(I I I I I)}\left(\tau_{i}\right) \cdot w_{g}\left(\tau_{i}\right)^{2}\right]
$$

where $\varepsilon_{s(I ; I I I)}, \varepsilon_{g(I I ; I I)}$ - porosity of solid and gas phases in $I I$ and $I I I$ zones of the granulator chamber; $w_{s}, w_{g}$ - instantaneous values of particle and gas velocities, $\mathrm{m} / \mathrm{s}$.

The instantaneous value of the relate gas velocity was determined from a known dependence [15] taking into account the porosity of a fluidized bed in zone III (ascending) of granulator chamber: 


$$
\begin{gathered}
\operatorname{Re}\left(\tau_{i}\right)=\frac{\operatorname{Ar} \cdot \varepsilon_{g(I I I)}\left(\tau_{i}\right)^{4,75}}{18 \cdot 0.61 \sqrt{\operatorname{Ar} \cdot \varepsilon_{g(I I I)}\left(\tau_{i}\right)^{4,75}}} \\
w_{g}\left(\tau_{i}\right)=\frac{\operatorname{Re}\left(\tau_{i}\right) \cdot v}{d_{e}}
\end{gathered}
$$

An average instantaneous velocity of solid particles in first two stages of the cycle, $\mathrm{m} / \mathrm{s}$ :

$$
w_{s}\left(\tau_{i}\right)=\frac{\Delta \varepsilon_{g(I I ; I I)}}{\Delta \tau}=\frac{\varepsilon_{g(I I ; I I)}\left(\tau_{i-t}\right)-\varepsilon_{g(I I ; I I)}\left(\tau_{i}\right)}{\tau_{i}-\tau_{i-t}}
$$

Calculation of the hydraulic resistance in a fluidized bed caused by overcoming the friction forces between solid particles and the friction due to motion of gas was carried out according to the proposed author $[14,16-22]$ by the expression:

$$
\begin{gathered}
\sum \Delta P_{\text {friction }}\left(\tau_{i}\right)=\Delta P_{\text {gas friction }}\left(\tau_{i}\right)+\Delta P_{\text {solid friction }}\left(\tau_{i}\right) \\
\Delta P_{\text {gas friction }}(\tau)=2 \cdot f_{g} \cdot \varepsilon_{g(I I ; I I I)}\left(\tau_{i}\right) \cdot \rho_{g} \cdot w_{g}{ }^{2} \cdot H_{0} \cdot \frac{1}{D_{a}} \\
\Delta P_{\text {solid friction }}(\tau)=5,7 \cdot 10^{-2} \cdot \frac{1}{D_{a}} \cdot \varepsilon_{g(I I ; I I I)}\left(\tau_{i}\right) \cdot \rho_{g} \cdot w_{g(c r)} \cdot \theta \cdot H_{0} \cdot \sqrt{\mathrm{g} \cdot D_{a}} \\
\theta(\tau)=\frac{\varepsilon_{s(I I ; I I I)}(\tau) \cdot \rho_{s} \cdot w_{s}(\tau)}{\varepsilon_{g(I I ; I I I)}\left(\tau_{i}\right) \cdot \rho_{g} \cdot w_{g}(\tau)}
\end{gathered}
$$

Hydraulic resistance of a fluidized bed was determined by the expression proposed by authors $[14,16-22]$ :

$$
\Delta P_{\text {hydrostatic }}\left(\tau_{i}\right)=\mathrm{g} \int_{0}^{H_{i}}\left(\rho_{s} \cdot \varepsilon_{s(\text { average })}(\tau)+\rho_{g} \cdot \varepsilon_{g(\text { average })}(\tau)\right) d z
$$

where $H_{i}$ - value of a fluidized bed height at a certain time $\tau_{i}, \mathrm{~m}$.

Unlike to [14, 16-22], hydrostatic pressure is determined by taking into account the physical model:

$$
\Delta P_{\max }=\Delta P_{n o m}+\Delta P_{\text {bubble }}=\rho_{s} \cdot\left(1-\varepsilon_{0}^{\prime}\right) \cdot \mathrm{g} \cdot\left(H_{0}+\Delta H_{0}+d_{\text {bubble }(\max )}\right)
$$

where $\varepsilon_{0}{ }^{\prime}$ - porosity of a fluidized bed, taking into account formed and permanently existing gas torches; $d_{\text {bubble(max) }}$ - the maximum possible size of gas bubble at moment of breaking a bound from the gas torches.

In addition, the growth velocity of gas bubble is also determined taking into account the change in the porosity of a fluidized bed in $I I$ and $I I I$ zones of the granulator chamber: 


$$
w_{\text {bubble }}\left(\tau_{i}\right)=\frac{\Delta \varepsilon_{g(I I ; I I I)}}{\Delta \tau}=\frac{\varepsilon_{g(I I ; I I I)}\left(\tau_{i-t}\right)-\varepsilon_{g(I I ; I I I)}\left(\tau_{i}\right)}{\tau_{i}-\tau_{i-t}}
$$

Taking into account the model of displacement of mass of material from fixed volume of a fluidized bed $(A \times B \times H)$, the amount of mass of granular material ejected beyond the boundary bed (with the starting height $H_{0}+\Delta H_{0}$ ) is determined as:

$$
\Delta M_{(\max )}=\frac{\left(\Delta P_{\max }-\Delta P_{n o m}\right) \cdot F_{a}}{\mathrm{~g}} \cdot K_{\mathrm{a}}
$$

where $K_{a}$ - coefficient that take into account the narrowing of the granulator chamber in zone of the fractional pressure (for the design of GDD $K_{a}=0,85$ );

$\Delta P_{\text {nom }}$ - nominal value of the pressure difference of stationary bed, $\mathrm{Pa}$ :

$$
\Delta P_{\text {nom }}=\rho_{s} \cdot\left(1-\varepsilon_{0}\right) \cdot \mathrm{g} \cdot H_{0}
$$

$F_{a}$ - the cross-sectional area of the granulator chamber, with sizes $A \times B \times H_{0}, \mathrm{~m}^{2}$ :

$$
F_{a}=A \cdot B
$$

Then residual mass of a fluidized bed in apparatus is, $\mathrm{kg}$ :

$$
M_{\text {residual (min) }}=M_{0}-\Delta M_{\text {ejected }(\max )}
$$

or

$$
M_{\text {residual }}\left(\tau_{i}\right)=M_{0}-\Delta M\left(\tau_{i}\right)=V_{\text {bed }(0)} \cdot\left(1-\varepsilon_{g(\text { average })}(\tau)\right) \cdot \rho_{s}
$$

Therefore, the current value of residual hydrostatic pressure is determined as, $\mathrm{Pa}$ :

$$
\Delta P_{\text {hydrostatic }}\left(\tau_{i}\right)=\frac{M_{\text {residual }}\left(\tau_{i}\right) \cdot \mathrm{g}}{F_{a} \cdot K_{a}}
$$

Experimentally found that height of injection the vertical gas jet $\Delta$ in relation to the horizontal axis $x$ is $\Delta=0.5 y_{f}$.

To solve the equation (4) it was necessary to determine experimentally the dynamics of change in the average porosity of a fluidized bed $\varepsilon_{g(\text { average })}=f(\tau)$ and in zones of the granulator chamber $-\varepsilon_{I I}=f(\tau), \varepsilon_{I I I}=f(\tau)$.

According to the physical model, in the first stage, when bubble is forming, the height of a fluidized bed is:

$$
\begin{gathered}
H_{1}=H_{0}+\frac{\Delta h_{I I}+\Delta h_{I I I}}{2} \\
H_{1} \cdot\left(1-\varepsilon_{g(\text { average })}\left(\tau_{i}\right)\right)=H_{0} \cdot\left(1-\varepsilon_{0}\right) \\
H_{1}=\frac{H_{0} \cdot\left(1-\varepsilon_{0}\right)}{\left(1-\varepsilon_{g(\text { average })}\left(\tau_{i}\right)\right)}
\end{gathered}
$$


We accept that in zone $I$ (the downstream) porosity of a fluidized bed is $\varepsilon_{I}=$ const and $\varepsilon_{I}=\varepsilon_{0}$.

Maximum values of porosity in zone $I I-\varepsilon_{I I}=1,5 \varepsilon_{0}$ and in zone $I I I-\varepsilon_{I I I}=2 \varepsilon_{0}$ and are calculated from the minimum residual height $H_{\text {residual }}$.

Residual height of a fluidized bed in zone III after reaching the maximum value of porosity of a bed in III zone is defined as, m:

$$
H_{\text {residual III }}=\frac{H_{0} \cdot\left(1-\varepsilon_{g(I I I) \max }\right)}{\left(1-\varepsilon_{0}\right)}
$$

If the minimum permissible residual height of a fluidized bed in zone III is $H_{\text {residual (III) }}=\Delta+y_{f}$, then:

$$
\varepsilon_{g(I I) \max }=1-\frac{\left(\Delta+y_{f}\right) \cdot\left(1-\varepsilon_{0}\right)}{H_{0}}
$$

For the case when $H_{0}=0.32 \mathrm{~m}$ and $\Delta+y_{f}=0.12 \mathrm{~m}: \varepsilon_{g(I I I) \max }=0.76$.

Assuming that the chamber of an apparatus is in form of parallelepiped, then the increase in height of a fluidized bed over the zone $I$ can be written as follows:

$$
\Delta h_{I}=\Delta h_{I I}+\Delta h_{I I I}
$$

That is, $\Delta h_{I}$ is defined as the sum of decreases in the fluidized bed heights in zones $I I-$ $\Delta h_{I I}$ and $I I I-\Delta h_{I I I}$.

Values of these parameters are calculated by expressions:

$$
\Delta h_{I I}=\frac{H_{0} \cdot\left(\varepsilon_{g(I I)}\left(\tau_{i}\right)-\varepsilon_{0}\right)}{1-\varepsilon_{0}}
$$

$$
\Delta h_{I I I}=\frac{H_{0} \cdot\left(\varepsilon_{g(I I I)}\left(\tau_{i}\right)-\varepsilon_{0}\right)}{1-\varepsilon_{0}}
$$

Then, substituting (32) and (33) into equation (31), the increase in height in zone $I$ acquires the following form, $\mathrm{m}$ :

$$
\Delta h_{I}=\frac{H_{0} \cdot\left(\varepsilon_{g(I I I)}\left(\tau_{i}\right)+\varepsilon_{g(I I)}\left(\tau_{i}\right)-2 \cdot \varepsilon_{0}\right)}{1-\varepsilon_{0}}
$$

Proposed to determine the sliding down velocity of a material using the Bernoulli law, $\mathrm{m} / \mathrm{s}$ :

$$
w_{s l .}=\sqrt{2 \cdot \mathrm{g} \cdot H_{s l}}
$$

where $H_{s l}=\Delta h_{I(\max )}$ - the maximum excess of height (sliding down) of a fluidized bed increase over zone $I, \mathrm{~m}$.

Empirically determined that time of sliding down of a granular material $\tau_{s l}$. is $1 / 4$ from the total cycle time $\tau_{c}$ and is defined as, s: 


$$
\tau_{s l .}=\frac{\Delta h_{I(\max )}}{w_{s l .}}
$$

\section{Experimental verification of simulating the non-uniform jet-pulsating fluidization in an auto-oscillating mode}

For the steady hydrodynamic auto-oscillating mode of fluidization at the optimum value of the fluidization number $-K_{w}=1.43$ the dynamics of change in porosity of a fluidized bed in zones by method of video fixation is determined. For this mode gas velocity in slits of GDD ( $\left.w_{\text {slits }}=27.33 \mathrm{~m} / \mathrm{s}\right)$ significantly exceeds the velocity of blowing out the particles with an equivalent diameter $D_{e}=3.97 \mathrm{~mm}, w_{\text {slits }}=3.5 \cdot w_{\text {blow out }}$, and the energy injected by gas coolant, W:

$$
E_{\text {kin. }}=\frac{\left(m_{1}+m_{2}\right) \cdot w_{\text {slits }}^{2}}{2}=21.1
$$

here $m_{1} ; m_{2}$ - mass flow of gas coolant in slits of GDD $\left(m_{1}=0.04 \mathrm{~kg} / \mathrm{s} ; m_{2}=0.017 \mathrm{~kg} / \mathrm{s}\right)$.

As a result of an experimental study, the height of the gas torch is $y_{f}=0.08 \mathrm{~m}$ and was obtained an experimental dependence for determination dynamics of change in porosity of a fluidized bed in a fixed volume of the apparatus chamber:

$$
\varepsilon_{g}\left(\tau_{i}\right)=\varepsilon_{g(\min )}+A+A \cdot \sin \left(\frac{2 \cdot \pi}{T} \cdot\left(\tau_{i}-\tau_{c} \cdot(n-1)\right)-K_{\text {shift }}\right)
$$

where $\varepsilon_{g(\min )}-$ minimum value of a fluidized bed porosity (at $\tau=0$ ), obtained experimentally $\left(\varepsilon_{\text {g(average })(\min )}=0.45\right)$;

$A=\left(\varepsilon_{g(\max )}-\varepsilon_{g(\min )}\right) / 2-$ amplitude of oscillations;

$\varepsilon_{g(\max )}-$ maximum value of a fluidized bed porosity (at $\tau=0.75 \cdot \tau_{c}$ ), obtained experimentally $\left(\varepsilon_{g(\text { average })(\max )}=0.63\right)$;

$T$ - period of oscillations, s: $T=1.5 \cdot \tau_{c}$ - for the first two stages of the cycle $\left(\tau_{i}=0-0.75 \cdot \tau_{c}\right) ; T=0.5 \cdot \tau_{c}-$ for the third stage of the cycle $\left(\tau_{i}=0.75 \cdot \tau_{c}-\tau_{c}\right)$;

$n$ - ordinal of an oscillation, unit;

$K_{\text {shift }}=5 \cdot \pi / 10$ - magnitude of the phase shift of an oscillation.

Frequency of pulsations: $f=1 / \tau_{c}=1 / 0.6=1.67 \mathrm{~Hz}$.

The obtained dependence with correlation coefficient $\sigma=0.989$ describes the experimental data.

Values of function $\varepsilon_{g(\text { avarage })}=f(\tau)$ can be determined by the equation:

$$
\varepsilon_{g(\text { average })}\left(\tau_{i}\right)=\frac{\varepsilon_{g(I)}\left(\tau_{i}\right) \cdot V_{I}+\varepsilon_{g(I I)} \cdot V_{I I}+\varepsilon_{g(I I)}\left(\tau_{i}\right) \cdot V_{I I I}}{V_{I}+V_{I I}+V_{I I I}}
$$

where $\varepsilon_{g(I)}, \varepsilon_{g(I I)}$ and $\varepsilon_{g(I I)}$ - values of porosity of a fluidized bed respectively to a current zone of granulator chamber $(I, I I$ and $I I I)$, determined by experimental way;

$V_{I}, V_{I I}, V_{I I I}$ - volumes of zones respectively to a current zone $(I, I I$ and $I I I)$ in a fixed volume of the apparatus. 
Dynamics of change in porosity of a fluidized bed in a fixed volume of the apparatus chamber (average and in current zone (I, II and $I I I)$ of chamber) obtained as a result of experimental study is shown on Figure 3.

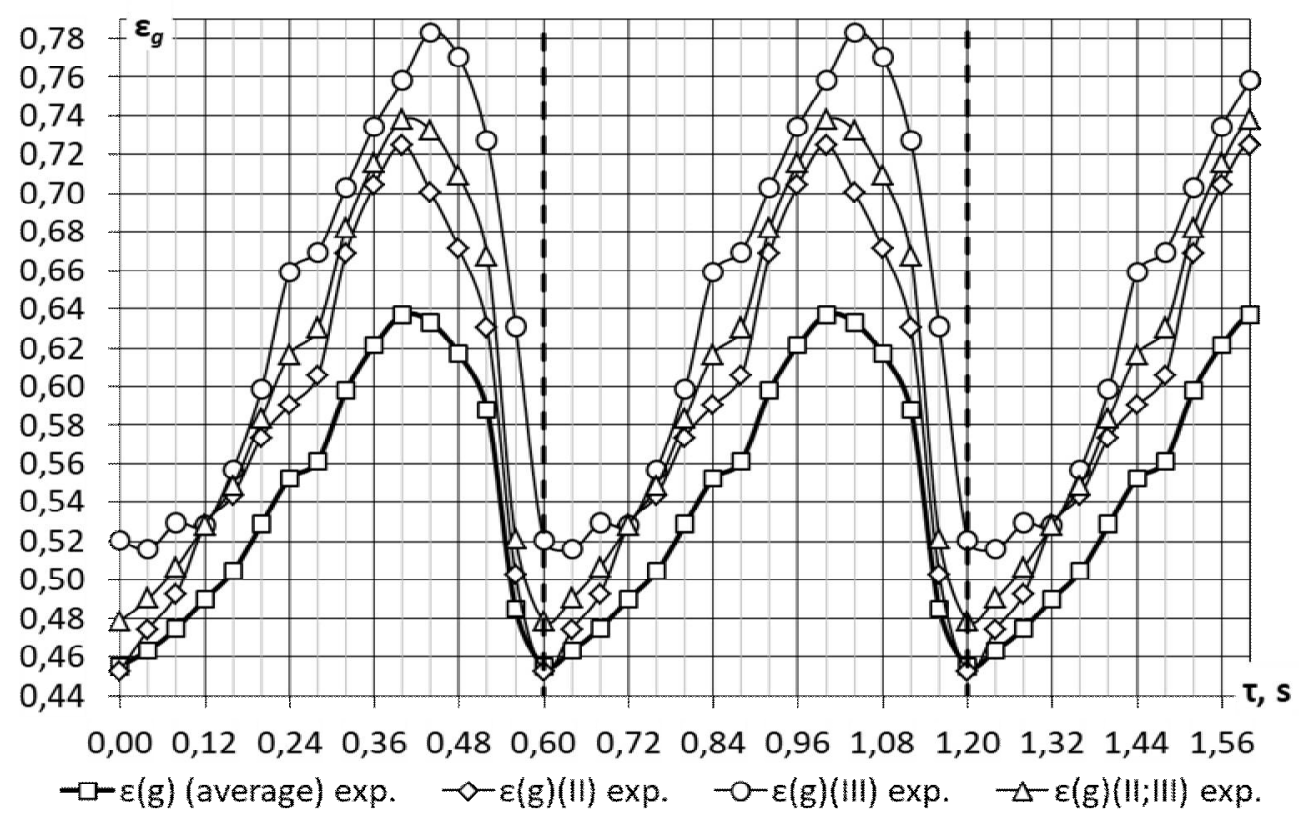

Figure 3. Dynamics of change in porosity of a fluidized bed obtained as a result of experimental study $-\varepsilon_{g}=f(\tau)$

As follows, velocity of change in porosity of a fluidized bed in a fixed volume of the bed is $\mathrm{d} \varepsilon / \mathrm{d} \tau=0.4$ for time $0 \leq \tau_{i} \leq 0.45 \mathrm{~s}$ and $\mathrm{d} \varepsilon / \mathrm{d} \tau=0.9$ for time $0.45 \leq \tau_{i} \leq 0.6 \mathrm{~s}$, that is more than 2 times higher.

A similar character of change is for the dynamics of change in porosity of a fluidized bed in zone $I I$ and $I I I$, which differ from the average only by values of an extreme points. Accordingly, the minimum and maximum values of porosity in zone $I I-\varepsilon_{g(I I)(\min )}=0.46$ and $\varepsilon_{g(I I)(\max )}=0.7$; in zone $I I I-\varepsilon_{g(I I I)(\min )}=0.49$ and $\varepsilon_{g(I I I)(\max )}=0.78$.

An average porosity of a fluidized bed in zone $I I$ and $I I I$ :

$$
\varepsilon_{g(I I I I I)}\left(\tau_{i}\right)=\frac{\varepsilon_{g(I I)}\left(\tau_{i}\right) \cdot V_{I I}+\varepsilon_{g(I I I)}\left(\tau_{i}\right) \cdot V_{I I I}}{V_{I I}+V_{I I I}}
$$

Dynamics of change in porosity of a fluidized bed (average and in zones $I I, I I I)$ obtained as a result of calculations, is shown on Figure 4. 


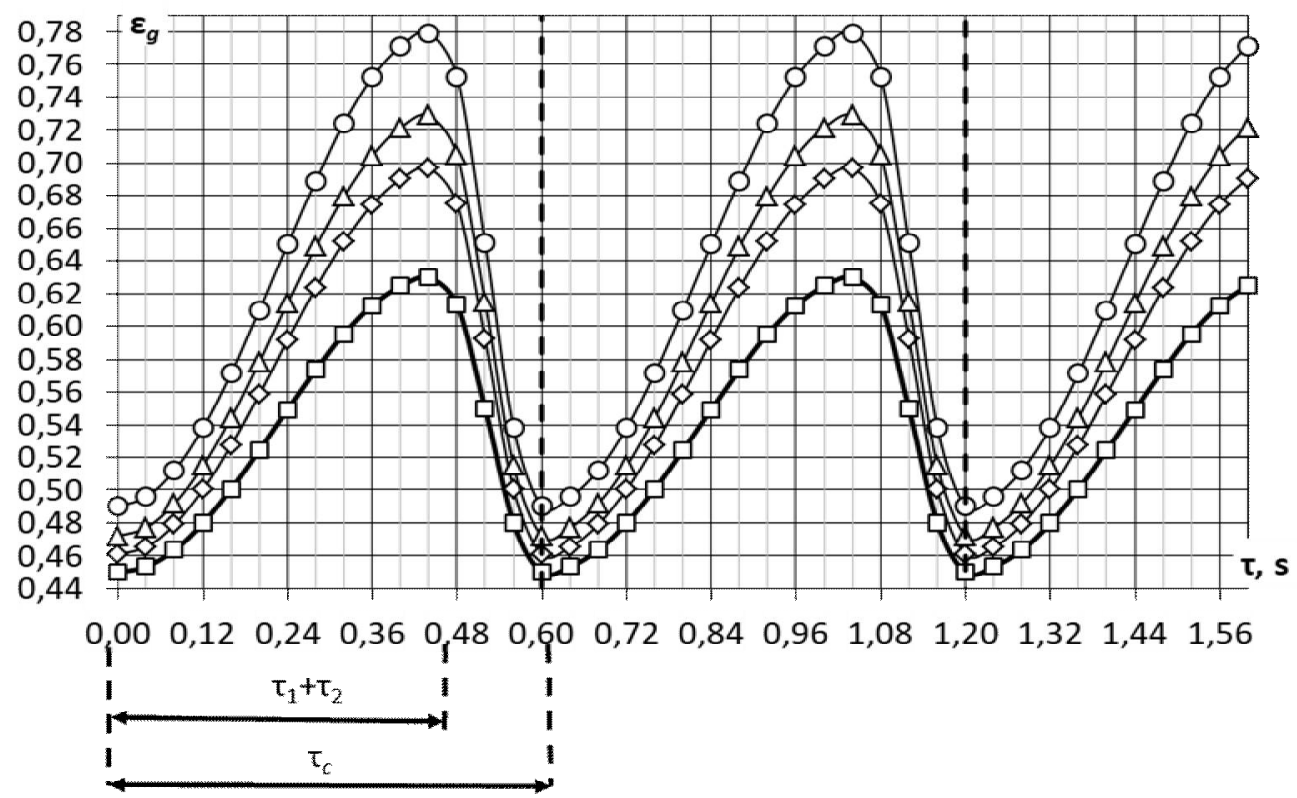

$\neg-\varepsilon(\mathrm{g})$ (average) calc. $\neg \varepsilon(\mathrm{g})(\mathrm{II})$ calc. $\multimap-\varepsilon(\mathrm{g})(\mathrm{III})$ calc. $\rightarrow-\varepsilon(\mathrm{g})(\mathrm{II} ;$;II) calc.

Figure 4. Dynamics of change in porosity of a fluidized bed obtained as a result of calculations $-\varepsilon_{g}=f(\tau)$

Based on the obtained values of the average porosity of a fluidized bed by the equation (20), the dynamics of mass change of the granular material bed in a fixed volume of the granulator chamber is determined as the ratio of mass of transferred material to initial $\Delta M_{i} / M_{0}$ (Figure 5).

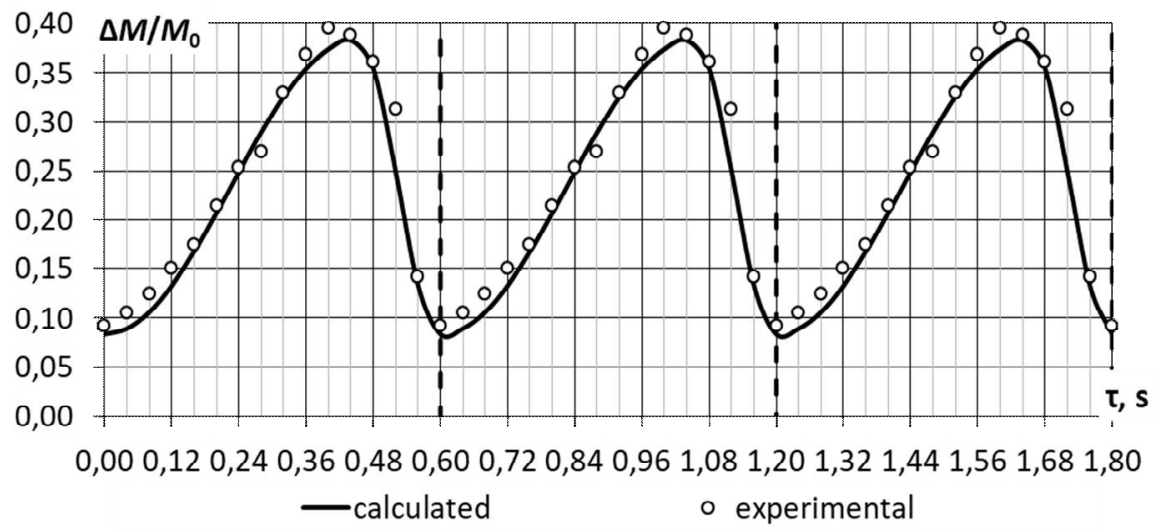

Figure 5. Dynamics of the change in mass of a bed in the over-bed space relative to the initial mass of bed $-\Delta M / M_{0}=f(\tau)$ 
Consequently, an application of the non-uniform jet-pulsating fluidization in an autooscillating mode with a frequency of $1.67 \mathrm{~Hz}$ allows ejecting into an outer-bed space up to $37 \%$ of the initial mass of bed, which in counteraction to a gas phase flow returns to the working volume of the granulator chamber. The estimated time of complete exchange of the surface in a fluidized bed is $3 \tau_{c}=3 \cdot 0.6=1.8 \mathrm{~s}$, which is a very important factor in the intensive processes of dehydration and granulation.

Verification of the mathematical model was made in form of the dynamics of change in the hydraulic resistance of a fluidized bed (Figure 6), and shows that calculated dependence $\Delta \mathrm{P}=f(\tau)$ by using the developed mathematical model with $\sigma=0.905$ describes the experimental data.

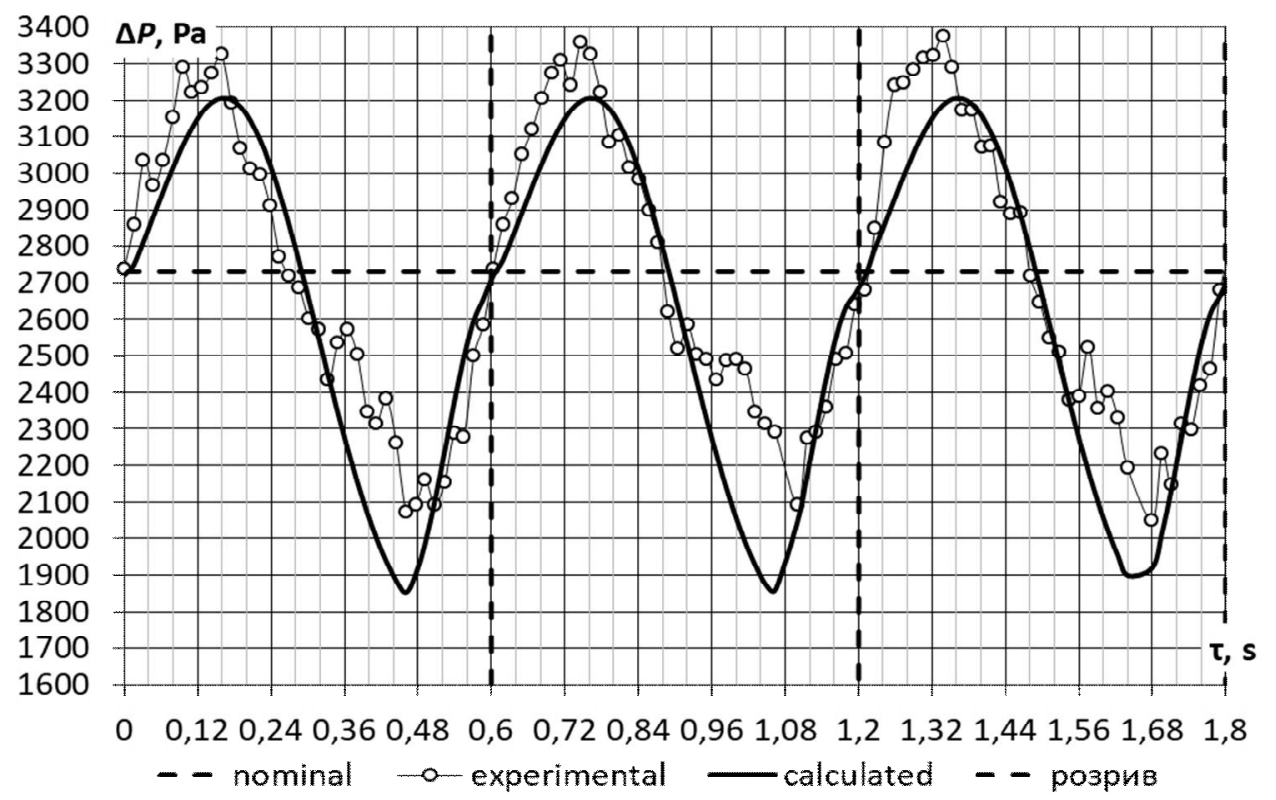

Figure 6. Dynamics of change in the hydraulic resistance of a fluidized bed $-\Delta P=f(\tau): \sigma=0.912$

The injection of kinetic energy with the gas phase $E_{k i n}=21.1 \mathrm{~W}$ leads to an increase in the total hydraulic pressure of a fluidized bed by $18.5 \%$. Taking into account the organization of motion of granular material in granulator chamber, this leads to an impulsive increase in the height of a fluidized bed (Figure 7) that is in accordance with increase of the potential energy of a fluidized bed and causes returning of the system into an equilibrium state. Estimated dependence $H_{b e d}=f(\tau)$ by using the developed mathematical model with $\sigma=0.941$ describes the experimental data. 


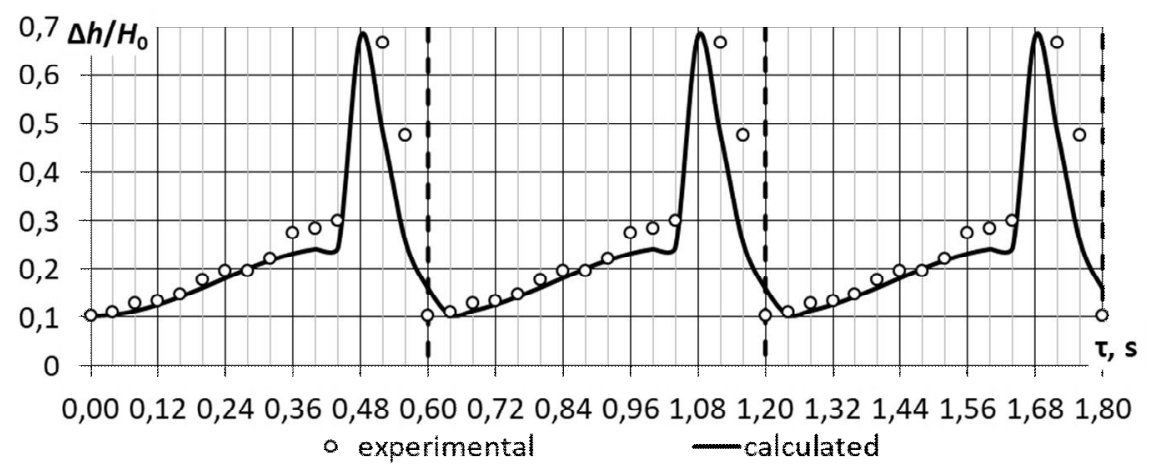

Figure 7. Dynamics of change in the height of a fluidized bed relative to the initial $-\Delta h / H_{0}=f(\tau): \sigma=0.941$

\section{Conclusions}

The developed mathematical model of non-uniform jet-pulsating fluidization in an auto-oscillatory mode adequately describes a new way of interaction of gas and solid phases. All statements of the physical model of the process, in which the non-uniform disperse system turns into the auto-oscillatory mode, are experimentally tested and confirmed.

\section{References}

1. Korniyenko Y., Hayday S., Semenenko D., Martynyuk O. (2013), Hranul'ovani azotno-kal'tsiyevo-huminovi tverdi kompozyty, modyfikovani bentonitom. Protses oderzhannya, Khimichna promyslovist' Ukrayiny, 5, pp. 46-51.

2. Kornienko Y., Gaidai S., Martyniuk O. (2014), Improved process to obtain granular humic fertilizers, available at: http://ela.kpi.ua/handle/123456789/11943.

3. Kornienko Y., Sememenko D., Martyniuk O. Gaidai S. (2015), The process of composite liquid systems dehydration in a fluidized bed using mechanical dispersant, available at: http://ela.kpi.ua/handle/123456789/11944.

4. Kornienko Y., Sachok R. (2008), Complex assessment of the efficiency of granulation process in dispersed systems, Chemistry \& chemical technology, 2(3), pp. 217-220.

5. Kornienko Y., Sachok R., Rayda V., Tsepkalo O. (2009), Mathematical Modeling of Continuous Formation Of Multilayer Humic-Mineral Solid Composites, Chemistry \& chemical technology, 3(4), pp. 335-338.

6. Kornienko Y., Haidai S., Liubeka A., Martynyuk O. (2016), Kinetic laws of the process of obtaining complex humic-organic-mineral fertilizers in the fluidized bed granulator, Ukrainian Food Journal, 5(1), pp. 144-154.

7. Kornienko Y., Haidai S., Liubeka A., Martynyuk O. (2016), Modelling of pulsating mode of fluidization when obtaining organic-mineral fertilizers, Ukrainian Food Journal, 5(4), pp. 781-794. 
8. Tuponogov V., Rizhkov A., Baskakov A., Obozhin O. (2008), Relaxation autooscillations in a fluidized bed, Thermophysics and Aeromechanics, 15(4), pp. 603-616.

9. Stroh A., Alobaid F., Hasenzahl M.T., Hilz J., Ströhle J., Epple B. (2015), Comparison of three different CFD methods for dense fluidized beds and validation by a cold flow experiment, Particuology, 862, pp. 245-259.

10. Tianyu Wang, Tianqi Tang, Yurong He, Hongliang Yi (2016), Analysis of particle behaviors using a region-dependent method in a jetting fluidized bed, Chemical Engineering Journal, 283, pp. 127-140.

11. Sasic S., Leener B., Johnsson F. (2005), Fluctuation and waves in fluidized bed systems: the influence of the air-supply system, Powder Technology, 153, pp. 176195.cxcxc

12. Buevich J., Minaev G. (1984), Jet fluidization, Chemistry, Moscow.

13. Kornienko Y., Haidai S., Semenenko D., Martynyuk O. (2013), Hranul'ovani azotnokal'tsiyevo-huminovi tverdi kompozyty, modyfikovani bentonitom. Protses oderzhannya, Khimichna promyslovist' Ukrayiny, 5, pp. 46-51.

14. Gidaspow D. (1994), Multiphase flow and fluidization: continuum and kinetic theory descriptions with applications, United Kingdom Edition, London.

15. Todes O., Tsitovich O. (1981) Apparati s kipiaschim zernistim sloem. Chemistry, p. 296.

16. Gidaspow D., Lin C., Seo Y. C. (1983). Fluidization in two-dimensional beds with a jet. Experimental porosity distributions, Industrial \& Engineering Chemistry Fundamentals, 22, pp. 187-193.

17. Gidaspow D., Arastoopour H., Abbasi E. (2017) Computational Transport Phenomena of Fluid-Particle Systems, Springer International Publishing, p. 192.

18. Gidaspow D., Chalermsinsuwan B., Piumsomboon P. (2014) In-depth system parameters of transition flow pattern between turbulent and fast fluidization regimes in high solid particle density circulating fluidized bed reactor, Powder Technology, 253, pp. 522-536.

19. Taghipour F., Ellis N., Wong C. (2005) Experimental and computational study of gassolid fluidized bed hydrodynamics. Chemical Engineering Science, 60, pp. 6857-6867.

20. Min J., Drake J., Heindel T., Fox R. (2010) Experimental Validation of CFD Simulations of a Lab-Scale Fluidized-Bed Reactor with and Without Side-Gas Injection, AIChE Journal "Particle Technology and Fluidization", 56(6), pp. 1434-1446.

21. Wang Q., Zhang K., Gu H. (2011) CFD simulation of pressure fluctuation characteristics in the gas-solid fl uidized bed: Comparisons with experiments, Petroleum Science, 8(2), pp. 211-218.

22. Inder R., Brink A., Hupa M. (2013) CFD modeling to study fluidized bed combustion and gasification, Applied Thermal Ingeneering, 52(2), pp. 585-614. 